\title{
Mixed large cell neuroendocrine carcinoma and adenocarcinoma of the gallbladder: a case report and brief review of the literature
}

Wei Liu ${ }^{1 \dagger}$, Lei Wang ${ }^{2+}$, Xiao-dong He ${ }^{1 *}$, Cheng Feng ${ }^{1}$, Xiao-yan Chang ${ }^{3}$ and Zhao-hui Lu ${ }^{3}$

\begin{abstract}
Large-cell neuroendocrine carcinoma (LCNEC) of the gallbladder is extremely rare. We present a 63-year-old Chinese female who was admitted with right upper quadrant pain and a quasi-circular tumor measuring $2.0 \mathrm{~cm}$ on the body of the gallbladder, as indicated by computed tomography. LCNEC combined with adenocarcinoma was immunohistochemically confirmed after open radical cholecystectomy. Postoperative recovery of this patient was uneventful, and no evidence of recurrence or metastasis was observed after 12 months of follow-up. LCNEC of the gallbladder is thought to be extremely rare and is usually found in combination with other histological carcinoma types, such as adenocarcinoma, as determined histologically. The prognosis is poor overall, but early detection with complete resection may result in a relatively good prognosis.
\end{abstract}

Keywords: Cholecyst, Neuroendocrine tumors, Adenocarcinoma, Neoplasms

\section{Background}

Neuroendocrine neoplasms (NENs) account for $1.25 \%$ of all malignancies, with the majority (66\%) occurring in the gastrointestinal tract, followed by the bronchopulmonary system (31\%). Other less frequent locations include the ovaries, testes, pancreas, and hepatobiliary system. Gallbladder NENs are particularly rare, and 278 cases were registered in the Surveillance, Epidemiology and End Results (SEER) from 1973 to 2005, only representing $0.5 \%$ of all NENs and approximately $2 \%$ of all gallbladder cancers $[1,2]$. Among all NENs originating in the gallbladder, large-cell neuroendocrine carcinoma (LCNEC) is exceedingly rare, and the first case worldwide was reported in 2000 [3]. To date, although several case reports of gallbladder LCNEC have been published [3-16] (Table 1), its biological behavior, the appropriate treatment modalities, and the overall patient prognosis remain largely unclear. Herein, we report a rare case of gallbladder LCNEC and present a brief literature review

\footnotetext{
* Correspondence: surgerypumch@sina.com

${ }^{\dagger}$ Equal contributors

'Department of General Surgery, Peking Union Medical College Hospital, Chinese Academy of Medical Sciences and Peking Union Medical College, 1\# Shuaifuyuan, Dongcheng District, Beijing 100730, China

Full list of author information is available at the end of the article
}

to contribute to the increased understanding of the clinical features of this disease.

\section{Case presentation}

A 63-year-old woman came to our emergency room on 14 July 2013, with a history of intermittent right upper quadrant pain that began 3 months prior. Ultrasound indicated no other anomalies, except for a focal thickening of the gallbladder wall. Computed tomography (CT) showed a suspected mass measuring $0.6 \times 0.3 \mathrm{~cm}$ on the gallbladder plica (Figure 1a). Because she had a past medical history of cholecystitis, we could not clearly determine whether the mass was a tumor or only thickened mucosa; thus, watchful follow-up was recommended to the patient. On the $29^{\text {th }}$ of October 2013, the patient returned to our clinic, and CT scan revealed a $2.0 \times$ $1.8 \mathrm{~cm}$ quasi-circular tumor located on the body of the gallbladder in the same location as the mass detected 3.5 months earlier, with significant enhancement in the portal venous phase (Figure 1b). The results of laboratory tests, including tests for tumor markers and hormonal profiles, were all within normal limits.

Laparoscopic cholecystectomy was performed, and an intraoperative frozen pathological section indicated that the lesion was malignant. Immediately thereafter, open 
Table 1 Clinicopathological features of 17 cases of large-cell neuroendocrine carcinoma of the gallbladder

\begin{tabular}{|c|c|c|c|c|c|c|c|c|c|c|}
\hline Number & Author [ref.] & Gender/age & Presentation & $\begin{array}{l}\text { Tumor } \\
\text { location }\end{array}$ & $\begin{array}{l}\text { Tumor size } \\
(\mathrm{cm})\end{array}$ & $\begin{array}{l}\text { Liver } \\
\text { invasion }\end{array}$ & Metastasis & Other component & Treatments & $\begin{array}{l}\text { Prognosis, follow-up } \\
\text { (month) }\end{array}$ \\
\hline 1 & Papotti et al. [3] & $M / 50$ & Unclear & Unclear & $<1$ & - & - & $A C$ & Cho & DFS, 12 \\
\hline 2 & Papotti et al. [3] & $M / 65$ & Unclear & Fundus & 2.5 & - & Liver & - & Cho & Died, 14 \\
\hline 3 & Jun et al. [4] & $M / 55$ & AP, jaundice & Unclear & Unclear & Unclear & Lymph node & - & Needle biopsy, Che & Died, 1 \\
\hline 4 & Jun et al. [4] & $F / 67$ & AP & Unclear & Huge & + & Lymph node & - & Needle biopsy, Che & Died, 10 \\
\hline 5 & Noske and Pahl [5] & $\mathrm{F} / 81$ & AP, jaundice & Neck & 5 & + & Bone & Adenosquamous & Palliative surgery & Unknown \\
\hline 6 & Oshiro et al. [6] & $\mathrm{F} / 55$ & Back pain, fever & Body & 4.9 & - & - & AC, SCNEC & Radical Cho & DFS, 20 \\
\hline 7 & Shimono et al. [7] & $F / 64$ & AP & Unclear & 11.5 & + & - & - & $\begin{array}{l}\text { Che, Rad, extended } \\
\text { hepatectomy }\end{array}$ & DFS, 36 \\
\hline 8 & lype et al. [8] & M/85 & $\begin{array}{l}\text { Anorexia, } \\
\text { weight loss }\end{array}$ & Fundus & 1.5 & - & Unclear & $A C$ & Cho, Che & Died, 21 \\
\hline 9 & Lin et al. [9] & $F / 65$ & $\begin{array}{l}\text { Cushing's } \\
\text { syndrome }\end{array}$ & Body & Unclear & - & - & -(ACTH-producing) & Radical Cho, Che & Died, 2 \\
\hline 10 & Sato et al. [10] & $F / 68$ & Negative & Fundus & 3 & + & Lymph node & $A C$ & $\begin{array}{l}\text { Cho, extended } \\
\text { hepatectomy }\end{array}$ & DFS, 12 \\
\hline 11 & Paniz et al. [11] & $F / 48$ & AP & Fundus & 3.5 & + & Unclear & $A C$ & $\begin{array}{l}\text { Cho, extended } \\
\text { hepatectomy }\end{array}$ & Unknown \\
\hline 12 & $\begin{array}{l}\text { Al-Brahim and } \\
\text { Albannai [12] }\end{array}$ & $M / 45$ & AP, jaundice & Fundus & 5.7 & + & Unclear & $A C$ & Cho, Che & Unknown \\
\hline 13 & Okuyam et al. [13] & $M / 64$ & $\begin{array}{l}\text { Abdominal } \\
\text { fullness }\end{array}$ & Fundus & 2.5 & + & Lymph node & - & Biopsy, Che & Died, 22 \\
\hline 14 & Nakagawa et al. [14] & $M / 56$ & Exophthalmos & Unclear & 9 & + & Multiple & $A C$ & Che, Rad & Died, 36 \\
\hline 15 & Meguro et al. [15] & $F / 54$ & Negative & Unclear & Unclear & - & - & $A C$ & $\begin{array}{l}\text { Cho, extrahepatic bile duct } \\
\text { resection }\end{array}$ & DFS, 24 \\
\hline 16 & Russo et al. [16] & $M / 59$ & AP & Body & 4 & + & Lymph node & Mucinous carcinoma & Radical Cho & Unknown \\
\hline 17 & Current study, 2014 & $F / 63$ & AP, fever & Body & 2.0 & - & - & $A C$ & Radical Cho & DFS, 12 \\
\hline
\end{tabular}

AP, abdominal pain; AC, adenocarcinoma; ACTH, adrenocorticotropic hormone; Che, chemotherapy; Cho, cholecystectomy; DFS, disease-free survival; F, female; M, male; Rad, radiotherapy; SCNEC, small-cell neuroendocrine carcinoma. 

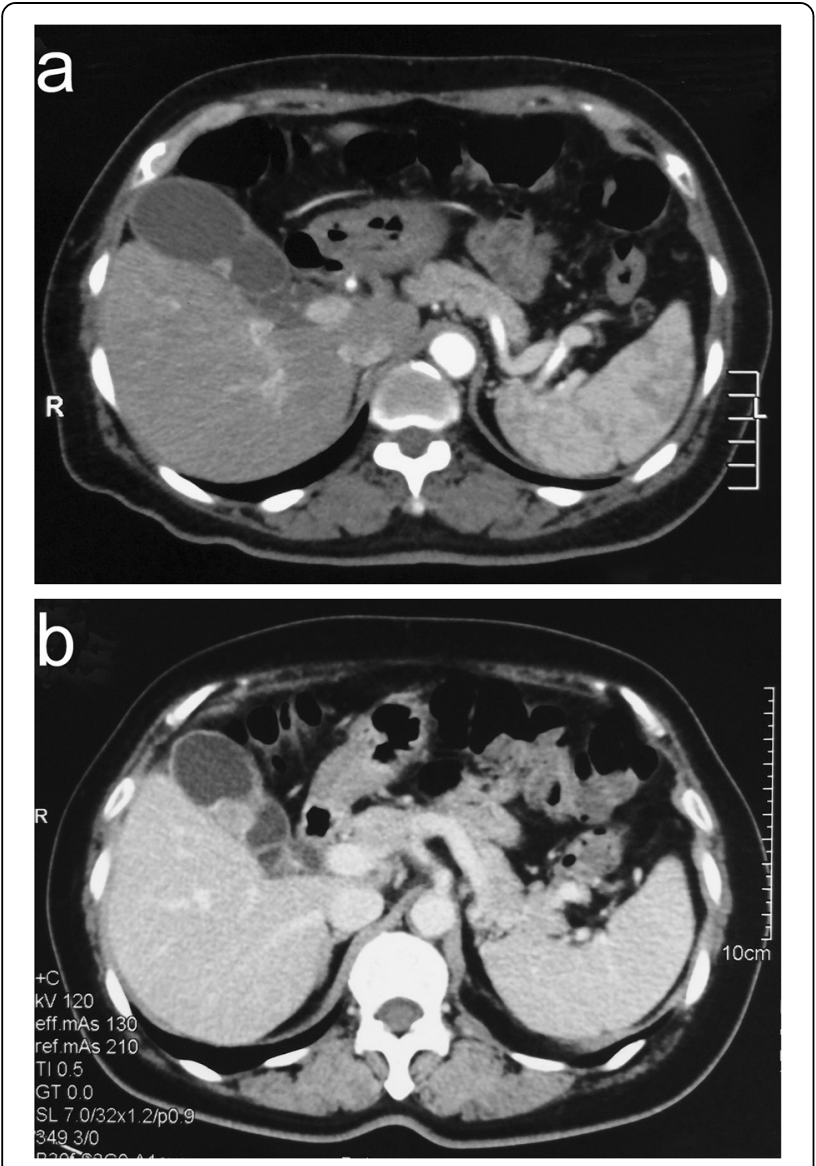

Figure 1 A fast-growing tumor located on the body of the gallbladder. (a) Computed tomography showed a suspected mass, measuring $0.6 \mathrm{~cm}$, on the gallbladder plica 3.5 months prior. (b) At admission 3.5 months later, $C T$ showed a $2.0 \times 1.8 \mathrm{~cm}$ quasi-circular mass located on the body of gallbladder, with significant enhancement in the portal venous phase.

radical cholecystectomy with resection of a wedge of the liver and the hepatoduodenal lymph nodes was performed. The gross specimen showed a cauliflower-shaped mass, and microscopically, the tumor consisted of the following two components: moderately differentiated adenocarcinoma and poorly differentiated large-cell neuroendocrine carcinoma (Figure 2a,b). Immunohistochemically, the neuroendocrine cells exhibited the strong expression of the neuroendocrine markers chromogranin A (Figure 2c) and synaptophysin (Figure 2d). In addition, these neuroendocrine cells showed a Ki67 index of over $80 \%$. There was no evidence of serous or liver invasion or lymph node or distant metastasis. Thus, this lesion was assigned a final classification of pT2NOM0 stage II, according to the Union Internationale Contre le Cancer guidelines. The postoperative course of this patient was uneventful, and the carcinoma did not recur during a 12-month followup period.
The present case report is in compliance with the Helsinki Declaration and has been approved by ethics committee of Peking Union Medical College Hospital.

\section{Discussion}

According to the latest World Health Organization (WHO) classification published in 2010 [17], NENs are classified into the following four general categories that are mainly based on mitotic count and the Ki67 proliferation index: (1) well differentiated neuroendocrine tumor (NET) or grade 1 tumor, with a mitotic count of $<2 / 10$ per high-power fields (HPF) and a Ki67 of $\leq 2 \%$, such as a typical carcinoids; (2) intermediate differentiated NET or grade 2 tumor, with a mitotic count of between 2 and 20/ 10 HPF and a Ki67 of 3\% to 20\%, such as an atypical carcinoids; (3) poorly differentiated neuroendocrine carcinoma (NEC) or grade 3 tumor, with a mitotic count of $>20 / 10$ HPF and a Ki67 of $>20 \%$, which includes small-cell and large-cell NECs; and (4) mixed adenoneuroendocrine carcinoma (MANEC), histologically exhibiting concomitant adenocarcinoma (or other components) and NEC concomitantly. Primary gallbladder small-cell NEC (GBSCNEC) is particularly rare, with only 74 cases described until 2011 [18]. Large-cell neuroendocrine carcinoma of the gallbladder (GB-LCNEC) is exceedingly rare and was first reported by Papotti in 2000 [3]. The histological features of LCNEC are as follows: (1) positivity for neuroendocrine markers, among which chromogranin A and synaptophysin are the most commonly identified; (2) a mitotic count exceeding 20/10 HPFs or a Ki67 index of over $20 \%$; and (3) a specific NET pattern of an organoid structure, rosette formation, palisading, and trabecular arrangement, as well as prominent nuclei that are over three times the diameter of a lymphocyte. Although more than ten cases of GB-LCNEC have been reported in the English literature to date (Table 1), there is a paucity of data on this tumor type.

We reviewed a series of 17 GB-LCNECs, including 16 previously reported cases and our present case. This series of GB-LCNECs included reports of 6 (35\%) pure LCNECs and 11 (65\%) LCNECs combined with other histological components, including 9 concomitant with adeno-, one with adenosquamous-, and one with mucinous carcinoma. Patients with mixed histological components were classified as having MANEC according to the WHO 2010 classification [17]. Only one tumor was found to be a functional $\mathrm{ACTH}$-producing tumor in this series.

Enterochromaffin cells, the precursor cells of NENs, are distributed throughout the gastrointestinal tract, bronchus, endocrine glands, and skin. These are also common sites of NEN. The gallbladder mucosa in the fundus and body is devoid of neuroendocrine cells, which may appear after intestinal metaplasia due to chronic inflammation. This fact explains why NENs rarely occur in the gallbladder. Virtually 


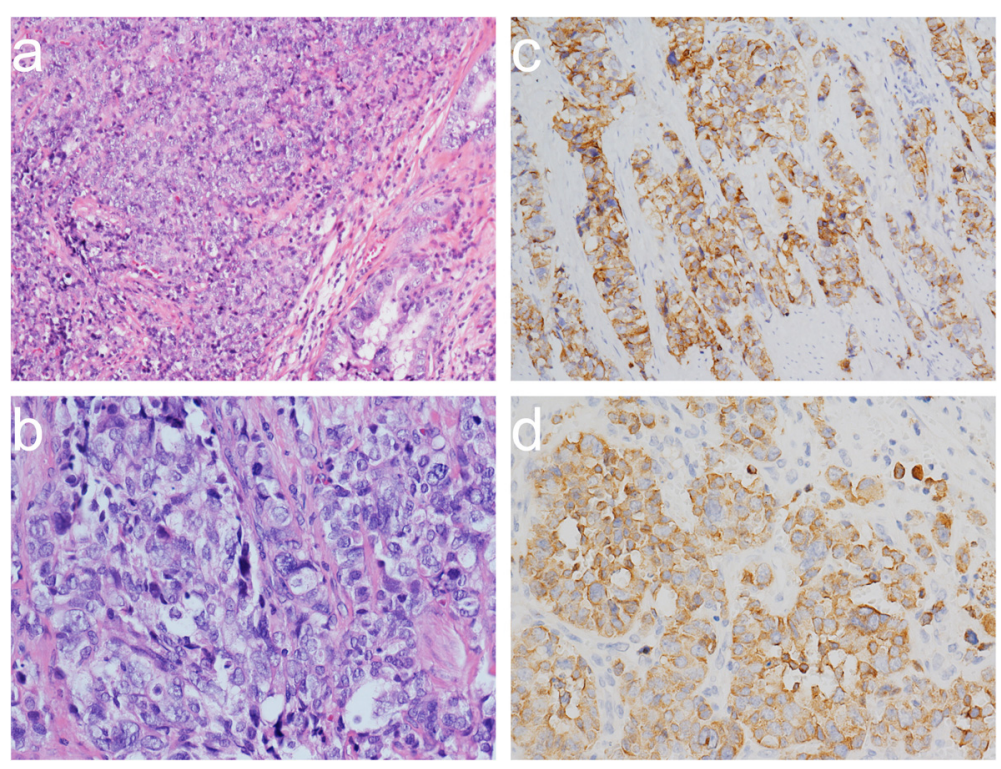

Figure 2 Pathologically demonstrated mixed large-cell neuroendocrine carcinoma and adenocarcinoma of the gallbladder. (a) A low-power view (H\&E, 100x) demonstrating the combination of a majority of poorly differentiated large cell neuroendocrine carcinoma (LCNEC) cells and a minority of moderately differentiated adenocarcinoma cells (right lower quadrant). (b) A high-power view (H\&E, 400X) demonstrating that the neuroendocrine carcinoma cells were large in size, polygonal, and contained high numbers of mitotic figures. (c) Immunohistochemical staining showing that the LCNEC cells were positive for chromogranin A. (d) Immunohistochemical staining showing that the LCNEC cells were positive for synaptophysin.

all published reports on gallbladder NENs describe coexisting gallstones and chronic cholecystitis [19]. Our patient presented non-specific vague abdominal pain in the right upper quadrant, which is a typical symptom of cholelithasis and should be considered a pathogenic basis of NEC.

Similar to most previously reported cases of NEC, the clinical symptoms and radiological findings of our patient were nonspecific. According to the descriptions of the series of 17 GB-LCNECs, abdominal pain (8/17, 47\%) was the most common symptom. Other symptoms, including fever, jaundice, and weight loss, were also nonspecific. SCNEC and LCNEC were confirmed to be genetically similar and distinct from well-differentiated NETs [20]. LCNEC was thought to exhibit similar aggressive behavior and early metastasis compared with SCNEC [4]. Among the 17 GB-LCNECs described, nine (53\%) were diagnosed with direct hepatic invasion, and eight (47\%) were identified with metastasis in the lymph nodes, liver, or bone. Fortunately, our case showed no signs of liver invasion or distant metastasis, which may have been attributed to early detection.

Surgical resection, which has been determined to improve the prognosis of patients with NEC [21], is considered to be the main treatment for gallbladder NECs. The prognosis is very poor for patients with unresectable masses [22], although multimodal treatments, including chemotherapy and radiation therapy, have achieved good responses in some reports [7]. Follow-up results were reported for 13 of the 17. Among them, seven (54\%) died of the disease in a median time of 14 months, while the other six patients exhibited disease-free survival (DFS) after 12 to 36 months of follow-up. Four surviving patients had some similar characteristics, such as small tumor size and no liver invasion or metastasis, and they had undergone radical surgery. The other two successful treatments for patients with liver invasion or lymph node metastasis mainly rely on extended surgery with hepatectomy and lymph node dissection. The presence of the adenocarcinoma phenotype is thought to indicate poor prognosis [2]. However, we could not make a similar conclusion according to this series of the 17 GB-LCNECs.

\section{Conclusions}

LCNEC of the gall bladder is extremely rare and is usually present along with other carcinoma types, such as adenocarcinoma, as determined histologically. The patient prognosis is poor overall, but early detection with complete resection may result in a relatively good prognosis.

\section{Consent}

Written informed consent was obtained from the patient for publication of this case report and any accompanying images. A copy of the written consent is available for review by the editor of this journal. 


\section{Abbreviations}

CT: computed tomography.; GB-LCNEC: large-cell neuroendocrine carcinoma of the gallbladder; GB-SCNEC: small-cell neuroendocrine carcinoma of the gallbladder; LCNEC: large-cell neuroendocrine carcinoma; MANEC: mixed adenoneuroendocrine carcinoma; NEC: neuroendocrine carcinoma; NEN: neuroendocrine neoplasm; NET: neuroendocrine tumor; SCNEC: small-cell neuroendocrine carcinomas.

\section{Competing interests}

The authors declare that they have no competing interests.

\section{Authors' contributions}

WL and LW reviewed the literature and wrote and edited the manuscript as major contributors. XDH conceptualized the case report and made substantial contributions to the design of the study. XYC and ZHL carried out the pathological analysis. CF was involved in treatment during hospitalization. All authors read and approved the final manuscript.

\section{Acknowledgement}

We wish to thank Xue-fei Wang for her language polishing. We also thank Michaela P. and Jacqueline C. who provided editing services on behalf of American Journal Experts. The work was supported by the National Natural Science Foundation of China (No.81372578).

\section{Author details}

'Department of General Surgery, Peking Union Medical College Hospital, Chinese Academy of Medical Sciences and Peking Union Medical College, 1\# Shuaifuyuan, Dongcheng District, Beijing 100730, China. ${ }^{2}$ Peking University Wu-Jieping Urology Center, Peking University Shougang Hospital, Peking University Health Science Center, 9\# Jinyuanzhuang Road, Shijingshan District, Beijing 100144, China. ${ }^{3}$ Department of Pathology, Peking Union Medical College Hospital, Chinese Academy of Medical Sciences and Peking Union Medical College, 1\# Shuaifuyuan, Dongcheng District, Beijing 100730, China.

Received: 14 December 2014 Accepted: 2 March 2015

Published online: 18 March 2015

\section{References}

1. The US National Cancer Institute. Surveillance Epidemiology and End Results (SEER) data base, 1973-2005. http://seer.cancer.gov/. 2008.

2. Yao JC, Hassan M, Phan A, Dagohoy C, Leary C, Mares JE, et al. One hundred years after 'carcinoid': epidemiology of and prognostic factors for neuroendocrine tumors in 35,825 cases in the United States. J Clin Oncol. 2008;26:3063-72.

3. Papotti M, Cassoni P, Sapino A, Passarino G, Krueger JE, Albores-Saavedra J. Large cell neuroendocrine carcinoma of the gallbladder: report of two cases. Am J Surg Pathol. 2000;24:1424-8.

4. Jun SR, Lee JM, Han JK, Choi BI. High-grade neuroendocrine carcinomas of the gallbladder and bile duct: report of four cases with pathological correlation. J Comput Assist Tomogr. 2006;30:604-9.

5. Noske A, Pahl S. Combined adenosquamous and large-cell neuroendocrine carcinoma of the gallbladder. Virchows Arch. 2006;449:135-6.

6. Oshiro H, Matsuo K, Mawatari H, Inayama Y, Yamanaka S, Nagahama K, et al. Mucin-producing gallbladder adenocarcinoma with focal small cell and large cell neuroendocrine differentiation associated with pancreaticobiliary maljunction. Pathol Int. 2008;58:780-6.

7. Shimono C, Suwa K, Sato M, Shirai S, Yamada K, Nakamura Y, et al. Large cell neuroendocrine carcinoma of the gallbladder: long survival achieved by multimodal treatment. Int J Clin Oncol. 2009;14:351-5.

8. lype S, Mirza TA, Propper DJ, Bhattacharya S, Feakins RM, Kocher HM. Neuroendocrine tumours of the gallbladder: three cases and a review of the literature. Postgrad Med J. 2009;85:213-8.

9. Lin D, Suwantarat N, Kwee S, Miyashiro M. Cushing's syndrome caused by an ACTH-producing large cell neuroendocrine carcinoma of the gallbladder. World J Gastrointest Oncol. 2010;2:56-8.

10. Sato K, Imai T, Shirota Y, Ueda Y, Katsuda S. Combined large cell neuroendocrine carcinoma and adenocarcinoma of the gallbladder. Pathol Res Pract. 2010;206:397-400.
11. Paniz Mondolfi AE, Slova D, Fan W, Attiyeh FF, Afthinos J, Reidy J, et al. Mixed adenoneuroendocrine carcinoma (MANEC) of the gallbladder: a possible stem cell tumor? Pathol Int. 2011;61:608-14.

12. Al-Brahim N, Albannai R. Combined large cell neuroendocrine carcinoma and adenocarcinoma of the gallbladder. Endocr Pathol. 2013;24:110-3.

13. Okuyama Y, Fukui A, Enoki Y, Morishita H, Yoshida N, Fujimoto S. A large cell neuroendocrine carcinoma of the gall bladder: diagnosis with 18FDG-PET/ CT-guided biliary cytology and treatment with combined chemotherapy achieved a long-term stable condition. Jpn J Clin Oncol. 2013;43:571-4.

14. Nakagawa T, Sakashita N, Ohnishi K, Komohara Y, Takeya M. Imprint cytological feature of large cell neuroendocrine carcinoma of the gallbladder: a case report. J Med Invest. 2013;60:149-53.

15. Meguro Y, Fukushima N, Koizumi M, Kasahara N, Hydo M, Morishima K, et al. A case of mixed adenoneuroendocrine carcinoma of the gallbladder arising from an intracystic papillary neoplasm associated with pancreaticobiliary maljunction. Pathol Int. 2014;64:465-71.

16. Russo S, Russo F, Maiello FM, Paolini B, Carrabba A, De Gregorio A. Biphasic large cell neuroendocrine carcinoma-pure mucinous carcinoma of the gallbladder (MANEC): a unique combination. Pathologica. 2012;104:185-9.

17. Rindi G. Nomenclature and classification of neuroendocrine neoplasms of the digestive system. In: Bosman FT, Carneiro F, Hruban RH, Theise ND, editors. WHO classification of tumours of the digestive system. 4th ed. Lyon, France: The International Agency for Research on Cancer; 2010. p. 13-4.

18. Mahipal A, Gupta S. Small-cell carcinoma of the gallbladder: report of a case and literature review. Gastrointest Cancer Res. 2011;4:135-6.

19. Eltawil KM, Gustafsson BI, Kidd M, Modlin IM. Neuroendocrine tumors of the gallbladder: an evaluation and reassessment of management strategy. J Clin Gastroenterol. 2010:44:687-95.

20. Yachida S, Vakiani E, White CM, Zhong Y, Saunders T, Morgan R, et al. Small cell and large cell neuroendocrine carcinomas of the pancreas are genetically similar and distinct from well-differentiated pancreatic neuroendocrine tumors. Am J Surg Pathol. 2012;36:173-84.

21. Moskal TL, Zhang PJ, Nava HR. Small cell carcinoma of the gallbladder. J Surg Oncol. 1999;70:54-9.

22. Modlin IM, Kidd M, Drozdov I, Siddique ZL, Gustafsson BI. Pharmacotherapy of neuroendocrine cancers. Expert Opin Pharmacother. 2008;9:2617-26.

\section{Submit your next manuscript to BioMed Central and take full advantage of:}

- Convenient online submission

- Thorough peer review

- No space constraints or color figure charges

- Immediate publication on acceptance

- Inclusion in PubMed, CAS, Scopus and Google Scholar

- Research which is freely available for redistribution

Submit your manuscript at www.biomedcentral.com/submit
C Biomed Central 